\title{
PERCEPÇÕES DE IDOSOS SOBRE ATIVIDADES DE AVENTURA NA NATUREZA
}

Recebido em: 06/02/2017

Aceito em: 10/11/2017

\author{
Adriana Aparecida da Fonseca Viscardi \\ Priscila Mari dos Santos \\ Giovana Zarpellon Mazo \\ Alcyane Marinho \\ Universidade do Estado de Santa Catarina (UDESC) \\ Florianópolis - SC - Brasil
}

RESUMO: Este artigo investigou as percepções sobre atividades de aventura na natureza de idosos participantes de um programa de extensão universitária Trata-se de uma investigação de campo, com abordagem qualitativa, desenvolvida por meio da aplicação de duas entrevistas semiestruturadas antes e após uma intervenção prática com atividades de aventura na natureza - stand up paddle e trilha. Para análise dos dados foi utilizada a técnica de análise de conteúdo. Os resultados indicam percepções positivas dos idosos sobre atividades de aventura na natureza e suas expectativas passam de apreensão e curiosidade, antes das vivências, para satisfação, orgulho e alegria após as práticas. Tais resultados sugerem a necessidade de esclarecimentos dessa população quanto à possibilidade de sua participação em atividades de aventura na natureza, bem como da preparação dos profissionais para atendê-la.

PALAVRAS CHAVE: Idoso. Natureza. Atividades de Lazer.

\section{ELDERLY PERCEPTIONS OF ADVENTURE ACTIVITIES IN NATURE}

ABSTRACT: This paper investigated the elderly's perceptions about adventure activities in nature in a university extension program. It is a qualitative field research developed through the application of two semi-structured interviews conducted before and after practical intervention of two adventure activities in nature - stand up paddle and trail. The technique of content analysis was used for data analysis. The results show that the participants have a positive perception about adventure activities in nature and spend their expectations of apprehension and curiosity, prior to the experience, into satisfaction, pride and joy after practice. These results suggest the need for explanations for this population about the possibility of their participation in adventure activities in nature, as well as professionals preparing to attend them.

KEYWORDS: Aged. Nature. Leisure Activities. 


\section{Introdução}

A população brasileira, acompanhando a tendência mundial, está passando por um processo de envelhecimento explicado pelo aumento quantitativo da população idosa - pessoas com 60 anos ou mais - e pela ampliação da expectativa de vida. Diante dessas alterações no perfil demográfico brasileiro são necessárias adequações nas políticas sociais do país, especialmente nas áreas da saúde, previdência e assistência social (IBGE, 2013). O envelhecimento é, geralmente, percebido negativamente pelo indivíduo, prejudicando sua autoimagem, autonomia e independência. Desse modo, a prática de atividade física orientada pode trazer benefícios para a sua vida, nos aspectos físicos, psicológicos e sociais (MAZO; LOPES; BENEDETTI, 2009).

Segundo Marcellino (2008), a chegada da aposentadoria, com a consequente diminuição das obrigações e aumento do tempo "livre" (tempo liberado do trabalho e de outras obrigações como as familiares, sociais, políticas e religiosas) deveria ser o "paraíso do lazer", momento oportuno para aproveitar a vida. Porém, mesmo sendo o lazer um direito garantido pela constituição brasileira (BRASIL, 1988), a realidade observada é bastante diferente. Fatores econômicos, como a redução dos ganhos mensais; questões sociais, como a supervalorização do trabalho; problemas de saúde e de locomoção, além de estereótipos diversos, são alguns dos fatores que limitam a participação dos idosos no lazer (MARCELLINO, 2008; OLIVEIRA; NASCIMENTO, 2014).

Historicamente, segundo Oliveira e Nascimento (2014), o idoso que era considerado como o alicerce da família no período pré-industrial, com o advento da modernização e da industrialização da sociedade, passa a ser desvalorizado, negado e considerado improdutivo durante muitos anos. No entanto, recentes pesquisas 
científicas relacionadas a essa população (MARCELLINO, 2008; MAZO; LOPES; BENEDETTI, 2009; SANTOS; et al., 2012) vêm mudando essa concepção, evidenciando a importância de uma população idosa ativa, independente, autônoma, integrada à sociedade e participativa. Nesse contexto, os campos da atividade física, dos esportes e do lazer estão recebendo novos delineamentos a fim de contemplar as mudanças que acompanham o envelhecimento populacional.

A crescente demanda pela reinserção do idoso na sociedade apoia-se na busca por novas possibilidades de melhorar sua qualidade de vida e envelhecer saudavelmente, encontrando no lazer um campo propício para a manifestação de seus interesses e preferências. Nesse sentido, devido não apenas ao envelhecimento da população, mas também a seus novos interesses, vêm aumentando as possibilidades de alternativas inovadoras de vivências no lazer pelos idosos, como as atividades de aventura na natureza (DIAS, 2006; VISCARDI et al.,2018).

Essas atividades, além de atenderem aos princípios em que, segundo Gobbi (1997), deve-se pautar a prática atividade física por idosos, a saber, a manutenção de sua aptidão funcional, de sua independência e autonomia; serem prazerosas; estimularem a criatividade; respeitarem suas limitações; serem recreativas e lúdicas; proporcionarem interação social com outros idosos e entre gerações e reforçarem sua autoconfiança e estima; possibilita ainda, segundo Dias (2006), a vivência de experiências estimulantes, desafiadoras e marcantes, a superação de limites, a busca pelo prazer e pela diversão e o contato com a natureza. Este contato, segundo Lavoura, Schwartz e Machado (2008), possibilita a troca entre o corpo e o meio, permitindo experimentação de novas sensações, sentidos, emoções e significados. Nesse sentido, a 
participação dos idosos nessas atividades os coloca diante de novos desafios e contribui para um padrão distinto de envelhecimento que merece investigação.

Este estudo compartilha das características de atividades de aventura na natureza apresentadas por Betrán (1995) como práticas esportivas que ocorrem privilegiadamente no lazer, em ambientes terrestres, aquáticos ou aéreos. Tais atividades apresentam características inovadoras e diferenciadas dos esportes tradicionais, principalmente quanto à motivação, às condições e aos meios utilizados para a sua execução. A realização dessas práticas, apesar de envolver riscos e perigos - controlados sempre que possível -, nem sempre demanda treinamentos intensivos prévios, podendo ser vivenciadas por diferentes públicos, independentemente do sexo ou da idade (BÉTRAN, 1995; MARINHO, 2003).

Partindo desses pressupostos, as atividades de aventura na natureza vêm despontando como uma possibilidade de estímulo para que o idoso permaneça fisicamente ativo, tenha melhor percepção das suas potencialidades e supere seus limites. A vivência dessas atividades pode contribuir com melhorias em sua autonomia, autoconceito e autoestima, podendo aumentar sua satisfação, sensação de bem-estar, prazer em viver e oportunizar interações sociais diferenciadas (DIAS, 2006; VISCARDI et al., 2018).

Embora estudos como os de Dias (2006), de Alves Junior (2012) e de VISCARDI et al. (2018) demonstrem aspectos positivos da prática de atividade de aventura na natureza por idosos, e Lavoura, Schwartz e Machado (2008) salientem que as experiências corporais vivenciadas no ambiente natural podem provocar uma complexa produção de pensamentos, sensações e emoções, além de mudanças de valores, condutas e estilo de vida; cabe ressaltar que, de acordo com Brookes (2003a), 
os indivíduos podem adquirir conhecimentos, habilidades e estratégias para lidar com as situações apresentadas durante a prática dessas atividades, inclusive, adaptando seu comportamento para adequar-se a elas. Contudo, isso não significa que essas atitudes serão aplicadas em outras situações da vida, ou que implicarão modificações no caráter ou a transformação do indivíduo. Embora sejam experiências válidas e que podem levar o praticante à reflexão, especialmente se bem conduzidas, esta crítica é pertinente e precisa ser ponderada constantemente.

Nesse contexto, frente ao interesse eminente pelas atuais possibilidades de vivências no lazer para os idosos, especificamente pelas atividades de aventura na natureza, e considerando o panorama nacional ainda restrito de pesquisas e estudos específicos sobre o assunto (ALVES JUNIOR, 2012; DIAS, 2006; VISCARDI et al., 2018), o presente trabalho tem como objetivo geral investigar as percepções dos idosos integrantes de um programa de extensão universitária sobre atividades de aventura na natureza, antes e após a prática de algumas delas (stand up paddle e trilha) e como objetivos específicos: identificar o interesse dos idosos pela prática de atividades de aventura na natureza; verificar como se dá a participação desses idosos nas atividades de stand up paddle e de trilha; e comparar as percepções antes e após essas vivências práticas.

\section{Metodologia}

Este estudo trata-se de uma investigação de campo, com corte transversal, e abordagem qualitativa dos dados. Participaram desta pesquisa 11 idosos integrantes de um programa de extensão de uma universidade pública de Santa Catarina. Nesse programa, os idosos podem participar de atividades educacionais, culturais, artísticas, 
físicas, fisioterapêuticas e de apoio psicológico, todas dentro das instalações universitárias, incluindo possibilidades como teatro, dança, ginástica, informática dentre outras. Dessa forma, não são oferecidas atividades de aventura na natureza como possibilidades de práticas no contexto deste programa de extensão universitária.

Não foram empregados procedimentos probabilísticos para a seleção dos participantes do estudo, tendo sido convidados todos os idosos integrantes do referido programa. Contudo, adotou-se como critérios de inclusão para participação no estudo: idosos que nunca tivessem praticado stand up paddle; regularmente matriculados no programa; apresentarem atestado médico para a intervenção; e aceitarem participar voluntariamente da pesquisa por meio da assinatura de um Termo de Consentimento Livre e Esclarecido. Inicialmente, a intenção era de que os idosos não tivessem praticado stand up paddle nem trilha; no entanto, durante o convite inicial para a participação do estudo, todos aqueles que atenderam aos critérios de inclusão mencionaram ter realizado trilha, pelo menos, uma vez na vida, mesmo que durante a infância ou juventude. Portanto, este critério precisou ser excluído, mantendo-se, apenas, o critério de nunca terem praticado stand up paddle.

Os dados foram obtidos por meio da utilização de dois roteiros de entrevista semiestruturada, elaborados especificamente para este estudo, sendo um destinado à aplicação antes e o outro após a intervenção prática, a qual, por sua vez, ocorreu durante um único dia contemplando duas atividades de aventura na natureza: trilha e stand up paddle. Também foram coletadas informações para caracterização dos participantes, tais como sexo, idade e escolaridade. Para registro das entrevistas foi utilizado um gravador de áudio, sendo posteriormente transcritas integralmente pela pesquisadora principal. 
Além disso, foi utilizado um diário de campo para anotações durante a intervenção prática.

A pesquisa foi aprovada pelo Comitê de Ética em Pesquisas Envolvendo Seres Humanos da Universidade do Estado de Santa Catarina por meio do parecer 881.069 de 22 de novembro de 2014. Após a aprovação, dentre 67 idosos interessados, 11 atenderam aos critérios de inclusão para participar do estudo.

No início do mês de março de 2015, os participantes responderam individualmente à primeira entrevista, aplicada pela pesquisadora principal deste estudo. Neste mesmo mês, foi realizada a intervenção prática conduzida por 3 profissionais de Educação Física, um deles especializado na prática do stand up paddle e por 2 instrutores especializados nessa modalidade, os quais instruíram e orientaram os participantes quanto às especificidades da trilha e do stand up paddle, bem como quanto à utilização dos equipamentos de segurança. Os profissionais de Educação Física acompanharam toda a intervenção e ministraram uma sessão de 10 minutos de exercícios de alongamento e aquecimento muscular, antes da prática, com o objetivo de preparar o corpo para as atividades e minimizar o risco de possíveis lesões; e uma sessão de 10 minutos de exercícios de relaxamento muscular, após a intervenção, com o intuito de diminuir o risco de possíveis dores musculares e de facilitar o retorno do corpo ao estado de repouso. O grupo também foi acompanhado por um técnico em enfermagem, que disponibilizou os equipamentos básicos de emergência, caso alguém necessitasse de algum atendimento, o que não ocorreu.

As atividades selecionadas foram realizadas na Lagoa do Peri, localizada na cidade de Florianópolis (SC). As atividades foram escolhidas pelo fato de Florianópolis (SC) ser uma cidade litorânea, com lagoas onde a prática de atividades aquáticas é 
comum e também por apresentar inúmeras trilhas com diferentes níveis de dificuldade, tornando possível a realização dessas atividades de forma segura e de acordo com as especificidades dessa população.

Nos dias subsequentes às atividades práticas, os idosos responderam, individualmente, à segunda entrevista, em horários previamente agendados e nos locais onde habitualmente realizam suas atividades do programa de extensão universitária ou em suas residências, sendo as entrevistas aplicadas pela pesquisadora principal em ambos os casos. As informações coletadas foram organizadas no software NVivo, versão 10.0, e analisadas por meio da técnica de análise de conteúdo categorial, na modalidade temática, organizada em três etapas principais: pré-análise; exploração do material e tratamentos dos resultados; inferência e interpretação, seguindo as orientações de Bardin (2009).

Emergiram das análises duas categorias mais amplas, a saber: o interesse dos idosos pelas atividades de aventura na natureza e as percepções e expectativas dos idosos sobre atividades de aventura na natureza. Três questões foram utilizadas a fim de analisar o interesse dos idosos pelas atividades de aventura na natureza, as duas primeiras referentes à primeira entrevista e a terceira à segunda entrevista, no intuito de verificar o conhecimento sobre essas atividades, as experiências anteriores a este estudo e a adoção de sua prática, respectivamente.

Por meio de oito questões foram investigadas as percepções e expectativas dos idosos sobre as atividades de aventura na natureza. Duas abordaram seus sentimentos, expectativas e percepções antes da intervenção prática, no propósito de conhecer o que pensam sobre as atividades de aventura na natureza e o que esperavam das vivências de trilha e de stand up paddle; e seis, após a intervenção prática, na intenção de verificar se 
as expectativas foram atendidas, quais emoções foram vivenciadas, facilidades e dificuldades encontradas e o que gostaram e não gostaram durante as práticas.

\section{Resultados e Discussões}

O grupo de participantes apresentou as seguintes características: três do sexo masculino e oito do sexo feminino, sendo a média de idade de 65 anos. Quanto ao nível de escolaridade um cursou o ensino fundamental incompleto; dois, ensino fundamental completo; cinco, ensino médio completo e três, ensino superior completo, um destes com pós-graduação. Quanto às atividades praticadas no programa de extensão universitária, um participa da atividade de dança, um de natação, um de natação e canto, quatro de hidroginástica, dois de ginástica, um de Pilates e um de teatro.

\section{Interesse dos Idosos pelas Atividades de Aventura na Natureza}

Quanto ao conhecimento sobre as atividades de aventura na natureza, Dora ${ }^{1}(65)$ declarou não conhecer nenhuma, porém, quando questionada se havia participado de alguma, mencionou a trilha. A maioria (10), apesar de nem sempre lembrar o nome, conseguiu descrever, pelo menos, uma atividade sobre a qual tinha conhecimento. Foram mencionadas 23 possibilidades, a saber: trilha/caminhada (7 idosos), surfe (3), paraquedismo (3), asa delta (3), rapel (3), tirolesa (3), stand up paddle (3), parapente (2), arvorismo (2), bungee jumping (2), escalada (1), caiaque (1), voo (1), sandboard (1), rafting (1), esqui na neve (1), montanhismo (1), vela (1), trilha de jipe e moto (1), acampamento (1), travessia em rio (1), balonismo (1). Outras atividades, que não as de aventura na natureza, também foram citadas, tais como: natação, hidroginástica, tênis,

\footnotetext{
${ }^{1}$ Os nomes citados são fictícios, com o intuito de preservar a identidade dos participantes deste estudo.
} 
futebol, ciclismo, equitação, basquete, arrancada de caminhão, pesca, escalar árvores, piquenique e passeio de barco.

Em estudo realizado na região metropolitana de Maringá (PR), Pimentel e Saito (2010) entrevistaram 207 indivíduos com idades entre 10 e 78 anos, sobre quais atividades de aventura conheciam. Os autores identificaram a menção a 40 delas, incluindo as que ocorrem em meio urbano. Um pequeno número de atividades como lutas, competições equestres e "rachas" também foram citados, demonstrando diferentes vieses no entendimento sobre essas atividades, o que também pode ser observado dentre os resultados do presente estudo. Tal fato demonstra que, apesar de conhecerem modalidades variadas, nem sempre fica claro para o público o conceito sobre as atividades de aventura na natureza, tratando-se de uma tendência natural para o dito "senso comum", visto que até mesmo na literatura científica sobre o assunto há conflitos sobre que termos utilizar e quais possibilidades fazem parte, ou não, das atividades de aventura na natureza.

Pode-se perceber, por meio das entrevistas, que o conhecimento sobre tais atividades está mais relacionado ao estilo de vida do que com o nível de escolaridade. Idosos que informaram estar engajados em outros grupos ou com seus familiares relataram maior número de atividades de aventura na natureza. Esta percepção vai ao encontro do estudo de Santos et al. (2012), o qual sugere que os suportes social e familiar influenciam positivamente nos aspectos físicos, cognitivos e emocionais do idoso, melhorando sua satisfação com a vida.

Quanto à prática prévia de atividades de aventura na natureza, Ana (62) declarou não ter praticado nenhuma, porém, no decorrer da entrevista, mencionou ter praticado trilha, assim como todos os outros participantes também haviam praticado esta atividade. 
Seis idosos afirmaram terem praticado outras atividades de aventura na natureza ou que envolvem o ambiente natural, como vela, montanhismo, natação no rio e no mar, acampamento, escalar árvores, teleférico, bondinho, piquenique e passeio de barco. Vários participantes se remetem à infância e à juventude, época em que desenvolviam atividades em grupos de amigos e passeios com a família.

Esses resultados diferem do estudo realizado por Dias (2006), em Brotas (SP), no qual foram entrevistados idosos praticantes de atividades de aventura na natureza. A autora verificou uma variedade de modalidades experimentadas por esses indivíduos, provavelmente em função da diversidade de oportunidades oferecidas pelas empresas da região e por se tratar de praticantes com experiência que variou de dois a 34 anos. Embora os participantes do presente estudo sejam idosos ativos, as modalidades oferecidas pelo programa de extensão se tratam de atividades ditas "convencionais" (hidroginástica, ginástica, natação, entre outras) e, apesar de os idosos viverem em um local propício às práticas de atividades de aventura na natureza, a maioria deles relatou não as realizar frequentemente, sugerindo como obstáculos a idade e as dificuldades relativas à saúde. Além disso, percebe-se, novamente, nessas respostas, os diferentes vieses no entendimento sobre essas atividades.

Com relação à possibilidade de adoção mais frequente da prática de atividades de aventura na natureza, oito idosos responderam positivamente e relataram motivos inerentes e relacionados às suas vivências e ao seu histórico pessoal, como diversão, superação, experimentar, estar consigo mesmo, gostar da atividade, dentre outros. Alguns investigados se referiram à convivência em grupo e outros ao contato com a natureza. Esses resultados se assemelham aos encontrados por Dias (2006), quais sejam: a influência da família e de amigos, seguida da curiosidade em conhecê-las; o contato 
com a natureza, a busca por novas experiências; e a necessidade de praticar atividade física.

Todos esses motivos elencados, bem como a empolgação e a vivacidade apresentadas pelos idosos no dia da intervenção prática, registradas pelo diário de campo e também verificadas por meio das respostas à segunda entrevista, refletem a importância de experiências variadas e significativas no lazer, que levem os idosos a superarem seus limites e perceberem suas potencialidades. De acordo com Marinho (2007), a participação efetiva no lazer ocorre quando este se aproxima da sensibilidade popular e da cultura, tornando-se um exercício de cidadania e expressão da autonomia dos envolvidos.

Outras três participantes afirmaram que adotariam a prática de atividades de aventura na natureza, mas com restrições. Ana (62) participaria, mas não gostaria que a atividade fosse muito prolongada. Eva (67) participaria na medida do possível, pois acredita que não tem saúde, que está envelhecendo e se sente cansada. Rute (66) se interessaria em praticar a cada dois meses, justificando não ter vontade e disposição para uma prática mais frequente.

Nesse sentido, Santos e Damico (2009) salientam a importância de considerar a biografia individual e a diversidade cultural presentes na história de cada um, bem como suas necessidades e preferências, para que os idosos não sejam oprimidos, obrigados a adotar um estilo de vida que lhes é imposto pela sociedade. Como em qualquer outra fase da vida, os idosos têm o direito de experimentar tais atividades e realizar suas escolhas, que devem ser respeitadas, bem como suas dificuldades e necessidades particulares que diferem de pessoa para pessoa. Segundo os mesmos autores, somente por meio de seu direito de escolha sobre o que fazer e como fazer, poderão continuar 
sendo protagonistas de suas próprias vidas e contribuindo, como cidadãos, para a melhoria da sociedade. Com base nessas considerações, as percepções e expectativas dos idosos sobre as atividades de aventura na natureza podem legitimar seu exercício de autonomia e identidade no contexto social.

\section{Percepções e Expectativas dos Idosos sobre Atividades de Aventura na Natureza}

No que se refere ao que os participantes pensam sobre essas atividades, algumas respostas evidenciam que apesar de os idosos terem uma percepção positiva, não acreditam aplicar-se à sua realidade, como em: "Acho que pra quem gosta, quem é aventureiro, deve ser uma maravilha! (e pra senhora?) [...] se hoje eu fosse adolescente, talvez me interessasse por alguma coisa" (Ana, 62) e em "Acho fantástico, é que depois de certa idade você já não pratica.” (Liz, 69).

Embora Oliveira e Nascimento (2014) evidenciem uma recente mudança na concepção relacionada ao idoso, afirmam que, durante muitos anos e, principalmente no Brasil, evidenciou-se uma desvalorização e não aceitação da velhice. Segundo Santos e Damico (2009), uma forma de envelhecer foi imposta, baseada em tentar não envelhecer. Ainda segundo os autores, no imaginário social, o melhor tempo da vida é a juventude, encorajando-se que suas características sejam copiadas em outras fases da vida. Alguns idosos acreditam que, para serem valorizados, precisam de algo entendido como sendo de jovem, como entusiasmo, alegria e disposição, esquecendo-se de que tais atributos não são exclusivos a determinada faixa etária, mas podem estar presentes em qualquer tempo da vida.

Outras respostas evidenciaram a percepção de perigo, a importância dos equipamentos de segurança e dos profissionais que trabalham na área, como em "A 
gente se sente mais vivo, com adrenalina, mas ao mesmo tempo são atividades perigosas, então devem ser feitas com uma equipe" (Ian, 66) e em “[...] esses esportes, geralmente, boa segurança eles têm, não é? Principalmente quando tem instrutores junto aos equipamentos" (Ivo, 64).

O risco e o perigo são temas sempre presentes nas discussões sobre atividades de aventura na natureza. Segundo Thomas e Raymond (1998), o ambiente desconhecido e a dúvida quanto à capacidade para a realização de determinada atividade excitam e desafiam os participantes, física e mentalmente, fazendo com que enfrentem incertezas reais. Apesar de o risco ser intrínseco e, por vezes, desejado nas atividades de aventura na natureza, os autores salientam que não significa que essas atividades devam ser necessariamente perigosas.

Autores como Thomas e Raymond (1998) e Matute e Agurruza (1995) alertam quanto à importância do planejamento para controles de redução e gerenciamento de risco. Dessa forma, o profissional deve estar preparado não apenas para avaliá-lo; mas também para adotar estratégias de controle para minimizá-lo, por meio da utilização de equipamentos de segurança, mudanças de percurso, substituição de atividades, entre outros; e, inclusive, ser competente na tomada de decisão sobre quando interromper ou não realizar a atividade.

Quanto aos equipamentos e à equipe profissional, Serôdio (2012), em seu estudo sobre a gestão das atividades de aventura na natureza, evidencia a necessidade de significativo investimento inicial em equipamentos e em conhecimento específico sobre a prática por parte dos gestores das empresas e instrutores. Matute e Agurruza (1995) evidenciam que os equipamentos têm a função não apenas de permitir e/ou facilitar a realização da atividade como também de prover maior segurança, minimizando riscos. 
Outro aspecto evidenciado no estudo de Serôdio (2012) refere-se à necessidade de haver uma relação de confiança entre praticante e instrutor, além de acompanhamento constante e personalizado ao praticante. Evidencia-se, assim, a importância do conhecimento e da preparação do instrutor que trabalha com essas atividades, em especial, quando se trata de um público diferenciado, como no caso dos idosos.

Segundo Marinho et al. (2016), a popularização das atividades de aventura na natureza acrescenta uma nova possibilidade de atuação ao profissional de Educação Física, evidenciando a necessidade da sua qualificação, bem como sua preparação para atender às exigências de intervenção nessas práticas. A competência profissional, segundo os mesmos autores, deve estar baseada em seus conhecimentos, habilidades e atitudes relacionadas à sua aplicação em contextos de complexidade e imprevisibilidade diversos. Dessa forma, dependendo da abordagem e da forma de instrução do profissional, os autores salientam que as atividades de aventura na natureza podem estimular a autonomia, a autodescoberta, a cooperação, a relação ser humano-natureza, a reflexão e a exploração de sensações e emoções.

Alguns participantes deste estudo se referiram a sentimentos como "Estou curiosa e com vontade" (Eva, 67). Sentimentos como a curiosidade, a apreensão e o medo, além do contato com a natureza, também foram mencionados pelos idosos investigados no estudo de Dias (2006). Miranda; Lacasa; Muro (1995) indicam, como uma das hipóteses para o crescimento do interesse por essas atividades, as profundas sensações e emoções que sua prática provocam, aliadas à escassez de formas apropriadas para expressão de emoções na vida cotidiana.

Outros mencionaram a natureza como em "[...] Acho bom, muito bom, no meio da natureza não tem nada melhor [...]" (Rute, 66) e "Acho que é um conhecimento da 
natureza [...]" (Rosa, 56). A busca pela natureza, segundo Bahia e Sampaio (2007), surge da necessidade de se reestabelecer uma relação entre homem-natureza, rompida em decorrência da urbanização, bem como um meio de fuga da vida cotidiana. Segundo Marinho (2007), esse regresso à natureza pode estar ligado tanto à conservação ambiental e à transformação social, por meio das diferentes e intensas trocas, bem como às reflexões que estas atividades proporcionam entre o ser humano e o meio, como a alienação e a depredação do ambiente, quando a natureza serve apenas como cenário ou local a ser explorado pelo mercado consumidor.

A questão financeira também foi lembrada na resposta “[...] não sei se não pratiquei por falta de oportunidade [...] muitas coisas que quis fazer, como pular de paraquedas, me faltaram condições financeiras [...]" (Rui, 61). O custo elevado para a realização de algumas modalidades foi mencionado nos estudos de Dias (2006), de Bahia e Sampaio (2007) e de Marinho (2007), como um obstáculo para a prática, concorrendo para a elitização desse mercado.

As respostas referentes às expectativas dos participantes acerca das vivências evidenciaram sentimentos positivos encontrados em algumas palavras e expressões, tais como experiências novas, vontade, diversão, curiosidade, expectativa boa, bem-estar e prazer. Contudo, também elucidaram sentimentos negativos como medo, insegurança e apreensão. De forma geral, quando os idosos eram incentivados a falar sobre cada uma das atividades que vivenciaram relatavam sensações boas com relação à trilha e de apreensão, tensão e curiosidade com relação ao stand up paddle, provavelmente por se tratar de uma atividade que seria realizada pela primeira vez e por ser no ambiente aquático. 
Assim como o risco, os sentimentos, as sensações e as emoções fazem parte das características das atividades de aventura na natureza. Matute e Agurruza (1995) afirmam que a combinação contraditória de ansiedade, prazer e excitação torna essas atividades divertidas, excepcionais e apaixonantes para muitos praticantes. Segundo Miranda; Lacasa; Muro (1995), tais vivências acumulam sensações corporais prazerosas aliadas às emoções, tendo, por esse motivo, um significativo potencial sensorial e emocional. Estes autores defendem, ainda, que é nessa dimensão subjetiva da experiência que está o motivo para a manutenção da prática.

Diferentemente do que afirma Marinho (2003), não foram citadas, nesta questão envolvendo expectativas, sensações de adrenalina, risco extremo e radicalidade. Por outro lado, bem-estar e outras sensações associadas à satisfação foram relatados. Tal fato pode ter acontecido em função de tratar-se de uma população idosa, com vivências distintas das experimentadas na sociedade contemporânea em que as atividades de aventura na natureza não eram tão disseminadas até então, diferenciando esse público dos demais e evidenciando a necessidade de uma preparação específica para seu atendimento.

Quando questionados sobre o atendimento de suas expectativas prévias, após a vivência das atividades de aventura na natureza, os idosos se manifestaram positivamente, como pode ser ilustrado pelas respostas: "Melhor do que eu esperava (risos). Pretendo até continuar [...]" (Rui, 61) e "Sim [...] me senti jovem, me senti bem" (Eva, 67). Tais afirmações demonstram que, para este grupo, a prática da trilha e do stand up paddle foram experiências positivas e prazerosas, que podem contribuir na superação de algumas limitações como o medo de experimentar, e em reflexões sobre sentir-se jovem ou se permitir vivenciar atributos tidos como oriundos da juventude. 
Sobre as emoções sentidas durante as vivências, as falas, bem como entonações e expressões da maioria dos idosos (captadas pelas observações e registradas no diário de campo), evidenciaram sensações de orgulho, satisfação e realização como pode ser notado, também, nos seguintes trechos das entrevistas: "Foi bem, me senti muito feliz, muito feliz mesmo [...] me senti muito realizada [...]" (Eva, 67) e "As emoções foram muitas. Até pela primeira vez que eu fiz, que me senti assim "nossa", me senti uma deusa (risos) me senti muito forte [...]" (Mara, 74). Porém, alguns também mencionaram a sensação de apreensão no início e durante a atividade de stand up paddle como em: "À medida que eu via o pessoal subindo na prancha, uns subindo outros caindo e aquela dificuldade eu pensei assim: meu Deus, o que eu estou fazendo aqui? [...]" (Cora, 65) e “[...] quando eu caí, eu fiquei nervosa, porque logo vi que o meu pé não alcançou lá no fundo [...]" (Dora, 65).

Da mesma forma, Dias (2006) encontrou em seu estudo, a superação de desafios e aspectos relacionados à autoestima e à autovalorização como significados das vivências dessas atividades. Por outro lado, em estudo realizado com jovens adultos por Lavoura; Schwartz e Machado (2008), emoções como o medo e insegurança foram as mais mencionadas. Ainda segundo esses autores, apesar de tais sentimentos serem observados negativamente, quando relacionadas às atividades de aventura na natureza podem assumir conotações de estímulo, excitação e prazer pela superação de desafios.

Brookes (2003b) ressalta que é possível que os participantes percebam mudanças positivas em seu autoconceito em alguns casos da prática de atividades ao ar livre; no entanto, tais mudanças não podem ser concebidas como formação ou transformação de caráter. O autor defende, ainda, que tais alterações não são, necessariamente, permanentes e adotadas em outras situações cotidianas vivenciadas 
por esses participantes. Tais perspectivas podem indicar que, apesar de a prática de atividades de aventura na natureza por idosos não ser uma solução irrefutável para todos os problemas enfrentados por essa população, principalmente quando relacionadas às atitudes adotadas diante de situações externas, se planejadas de forma adequada, segura e estimulante e vivenciadas prazerosamente, podem proporcionar inúmeros benefícios aos idosos.

No que se refere às dificuldades encontradas, Dora (65) mencionou ter sentido dificuldade na trilha em função do cansaço, e oito participantes mencionaram dificuldades com relação ao stand up paddle. As dificuldades citadas foram: (des) equilíbrio; ficar em cima da prancha; subir na prancha; interferência das marolas; ondas e vento ou dor; manejar e dominar a prancha; medo; perder a confiança e susto ao cair. Por outro lado, dois idosos relataram não ter sentido nenhuma dificuldade.

Tais respostas evidenciam desafios físicos e psicológicos enfrentados pelos idosos, divergindo das respostas encontradas por Dias (2006), nas quais as dificuldades mencionadas com mais frequência foram o alto custo para a realização, a falta de informação sobre as atividades e sobre quem pode fazer, o preconceito, vencer o medo e conhecer seus limites. É provável que tais discordâncias ocorram em função de os grupos possuírem tempos de prática diferentes.

Quanto às facilidades foram relatadas a trilha, ficar em cima da prancha e deslizar sobre a água; geralmente relacionadas às atividades em si. Estabelecendo-se uma comparação entre as dificuldades e facilidades, verifica-se que os dois idosos que não apontaram nenhuma dificuldade e outros cinco idosos que apontaram dificuldades no stand up paddle, mencionaram a trilha como facilidade. A trilha, provavelmente, pode ter sido a facilidade mais mencionada por estarem familiarizados com essa 
atividade. No entanto, três idosos que mencionaram como dificuldade ações relacionadas à prática do stand up paddle, também mencionaram esta experiência como facilidade, demonstrando com isso as contradições presentes nessas atividades, ora difíceis, ora fáceis. Nessas respostas e em alguns comentários dos idosos antes das vivências (registradas no diário de campo), percebe-se que as dificuldades estão relacionadas a fatores internos como insegurança na água (susto ao cair) e dor; e fatores externos relacionados às condições do ambiente (marola, onda, vento).

Matute e Agurruza (1995) destacam os componentes ambientais como ventos, ondas, correnteza, dentre outros, como fatores de risco dinâmicos das atividades de aventura na natureza. Nos casos em que esses componentes são acíclicos, com mudanças constantes de velocidade e direção, tais quais as rajadas de ventos, torna-se mais difícil prever as ações necessárias durante a prática. Essa situação foi percebida e mencionada por alguns praticantes neste e em outros momentos da entrevista.

Alguns participantes, quando questionados sobre o que mais gostaram nas vivências, mencionaram as atividades propriamente ditas como o stand up paddle, a trilha, o alongamento e o boiar. Por sua vez, outros idosos mencionaram o aspecto social como o relacionamento com o grupo, a convivência, a reunião, a camaradagem.

As respostas evidenciam que as atividades nas quais ocorrem interações sociais são muito valorizadas pelos idosos. Santos et al. (2012), em inquérito realizado em uma cidade de Minas Gerais, verificaram que as atividades no lazer, nas quais se estabelecem relações sociais, são as mais frequentadas por essa população, seja com familiares ou em grupos nos quais os participantes possuem interesses comuns, faixa etária e situações de saúde semelhantes, tendo maior oportunidade de interagir e 
dialogar sobre o cotidiano e as experiências vivenciadas, diminuindo, assim, o isolamento social.

Oito idosos relataram que não teve nada que eles não tenham gostado; Ivo (64) ficou desapontado porque não tentou voltar remando; Rui (61) não gostou dos pernilongos; e Dora (65) achou a trilha longa e com muitos morros. Essas respostas demonstram o predomínio da percepção positiva sobre as vivências, tanto com relação às atividades praticadas quanto com relação aos aspectos físicos, psicológicos e sociais, demonstrando que tais atividades podem ser vivenciadas e apreciadas por idosos, desde que programadas adequadamente.

Com base nos dados coletados, verifica-se o interesse e a curiosidade dos idosos em relação às atividades de aventura na natureza, além de sentimentos que se alternam entre apreensão e satisfação. Outros dois aspectos percebidos pelos idosos durante a participação nas atividades de trilha e de stand up paddle foram a importância das relações sociais e do contato com a natureza. Isso sugere que tais experiências tiveram uma conotação positiva para o grupo estudado.

\section{Considerações Finais}

Os resultados desta pesquisa indicam que o conhecimento sobre as diversas modalidades das atividades de aventura na natureza relaciona-se com o estilo de vida do idoso e sua participação em atividades com familiares e com outros grupos. As percepções sobre atividades de aventura na natureza são predominantemente positivas, embora inicialmente os idosos tenham relatado sentir que não fossem adequadas à sua idade. Suas expectativas passam de apreensão e curiosidade, antes das vivências, para satisfação, orgulho e alegria após a prática do stand up paddle e da trilha, indicando, 
inclusive, o interesse da maioria em continuar praticando e experimentando outras atividades de aventura na natureza.

No processo de envelhecimento, imbuído de contradições, tensões e conflitos pessoais e sociais, os idosos perceberam possibilidades diferenciadas de experimentar o corpo, a natureza e a aventura. Esses resultados podem contribuir para uma reflexão sobre a participação do idoso nas atividades de aventura na natureza, sugerindo a necessidade de esclarecer essa população quanto às possibilidades de vivências no lazer e da necessidade de preparação do mercado e dos profissionais para atendê-los.

Por se tratar de uma pesquisa desenvolvida com um grupo específico de idosos, incluindo poucos participantes, torna-se importante a realização de novas pesquisas sobre o assunto, avançando e superando as limitações deste trabalho. Estudos com maior número de participantes, especialmente idosos que não realizem atividade física, poderão possibilitar uma visão mais abrangente da percepção de idosos sobre as atividades de aventura na natureza.

\section{REFERÊNCIAS}

ALVES Jr, E. D. Atividades de aventura, tecnologias e envelhecimento. In: Tecnologias e atividades de aventura. Schwartz GM et al., organizadora. CBAA - CONGRESSO BRASILEIRO DE ATIVIDADES DE AVENTURA, 7. CIAA - CONGRESSO INTERNACIONAL DE ATIVIDADES DE AVENTURA, 1. Anais... São Paulo: Lexia; 2012. p. 23-29.

BAHIA, M. C.; SAMPAIO T. M. V. Lazer - meio ambiente: em busca das atitudes vivenciadas nos esportes de aventura. Revista Brasileira de Ciências do Esporte, Campinas, v. 28, n. 3, p. 173-189, 2007.

BARDIN, L. Análise de Conteúdo. Ed. rev. actual. Lisboa: Edições 70, 2009. 281 p.

BETRÁN, J. O. Las actividades físicas de aventura em la naturaleza: análise sociocultural. Apunts: Educación Física y Deportes, Barcelona, v.41, p. 5-8, 1995. 
BRASIL. Constituição (1988). Constituição da República Federativa do Brasil, 1988. Brasília: Senado $\quad$ Federal, $1988 . \quad$ Disponível em: http://www.presidencia.gov.br/legislacao .

BROOKES, A. A critique of neo-Hahnian outdoor education theory. Part one: Challenges to the concept of "character building". Journal of Adventure Education \& Outdoor Learning, v. 3, n. 1, p. 49-62, 2003a.

BROOKES, A. A critique of neo-Hahnian outdoor education theory. Part two: "the fundamental attribution error" in contemporary outdoor education discourse. Journal of Adventure Education \& Outdoor Learning, v. 3, n. 2, p. 119-32, 2003 b.

DIAS, V.K. A participação de idosos em atividades de aventura na natureza no âmbito do lazer: valores e significados. 2006. 119 f. Dissertação (Mestrado em Ciências da Motricidade) - Universidade Estadual Paulista, Rio Claro, 2006.

GOBBI, S. Idosos: Educação Física x Anti-Educação Física. Motriz, Rio Claro, v. 3, n. 2, p. 123-125, 1997.

IBGE - Instituto Brasileiro de Geografia e Estatística. Síntese de indicadores sociais: uma análise das condições de vida da população brasileira 2013. Rio de Janeiro, 2013.

LAVOURA, T. N.; SCHWARTZ, G. M.; MACHADO, A. A. Aspectos emocionais da prática de atividades de aventura na natureza: a (re) educação dos sentidos. Revista Brasileira de Educação Física e Esporte, São Paulo, v. 22, n. 2, p. 119-127, 2008.

MARCELLINO, N.C. Lazer e Humanização. 9. ed. Campinas: Papirus, 2008. 88 p.

MARINHO, A. Da aceleração ao pânico de não fazer nada: corpos aventureiros como possibilidades de resistência. In: MARINHO, A.; BRUHNS, H.T. (Org.). Turismo, lazer e natureza. Barueri: Manole, 2003. p. 1-28.

MARINHO, A. Lazer, meio ambiente e turismo: reflexões sobre a busca pela aventura. Licere, Belo Horizonte, v. 10, n. 1, p. 1-20, 2007.

MARINHO, A; SANTOS, P. M.; MANFROI, M. N., FIGUEIREDO, J. P; BRASIL, V. $Z$. Reflections about outdoor adventure sports and professional competencies of physical education students. Journal of Adventure Education and Outdoor Learning, Carlisle, v. 16, n. 1, p. 1-17, sep. 2016.

MATUTE, J. F.; AGURRUZA, B. E. Riesgo y actividades físicas em el médio natural: um enfoque multidimensional. Apunts: Educación Física y Deportes, Barcelona, v. 41, p. 94-107, 1995.

MAZO, G.Z.; LOPES. M. A.; BENEDETTI, T. B. Atividade física e o idoso: concepção gerontológica. 3. ed. Porto Alegre: Sulina, 2009. 318 p. 
MIRANDA J.; LACASA, E.; MURO, I. Actividades físicas em la naturaleza: un objeto a investigar. Dimensiones científicas. Apunts: Educación Física y Deportes, Barcelona, v. 41, p. 53-69, 1995.

OLIVEIRA, K. P. G.; NASCIMENTO, A. F. Revisando o lazer na terceira idade: uma proposta metodológica necessária. Licere, Belo Horizonte, v. 17, n. 3, p. 275-302, 2014.

PIMENTEL, G. G. A.; SAITO, C. F. Caracterização da demanda potencial por atividades de aventura. Motriz, Rio Claro, v. 16, n.1, p. 152-161, 2010.

SANTOS, C. L. S. et al. Autopercepção dos idosos sobre satisfação com a vida relacionada a interações sociais e lazer. Motricidade, v. 8, S2, p. 232-239, 2012.

SANTOS, F. C.; DAMICO, J. G. S. O mal-estar na velhice como construção social. Pensar a Prática, Goiânia, v. 12, n. 1, p. 1-9, 2009.

SERÔDIO, A. J. As atividades de natureza e lazer como fator de desenvolvimento. Motricidade, v. 8, S2, p. 228-231, 2012.

THOMAS, S.; RAYMOND, C. Risk and provider responsibility in outdoor adventure activities. Teacher Development: An international journal of teachers' professional development, v. 2, n. 2, p. 265-281, 1998.

VISCARDI, A. A. F.; SANTOS, P. M.; MAZO, G. Z.; MARINHO, A. Participação de idosos em atividades de aventura na natureza: reflexões sobre aspectos socioambientais. Movimento, Porto Alegre, v. 30, n. 53, p. 35-51, 2018.

\section{Endereço das Autoras:}

Adriana Aparecida da F. Viscardi

Rua Cel Luiz Caldeira, 105, apto 107, bloco C, Itacorubi

Florianópolis - SC - 88.034-110

Endereço Eletrônico: adrianaapfonseca@yahoo.com.br

Priscila Mari dos Santos

Servidão Dona Vitorina Lopes, LD30, Campeche

Florianópolis - SC - 88.066-026

Endereço Eletrônico: priscilamarisantos@hotmail.com

Giovana Zarpellon Mazo

Avenida Buriti, 680, Parque São Jorge

Florianópolis - SC - 88.034-500

Endereço Eletrônico: giovana.mazo@udesc.br

Alcyane Marinho

Rua Vereador Ramon Filomeno, 357, apto 1001, torre 1, Itacorubi

Florianópolis - SC - 00.034-495 
Adriana Aparecida da F. Viscardi, $\quad$ Percepções de Idosos Sobre Atividades de Aventura na Natureza Priscila Mari dos Santos,

Giovana Zarpellon Mazo e Alcyane Marinho

Endereço Eletrônico: alcyane.marinho@hotmail.com 